\title{
Is there anything left to learn? A report on the Fifth International Workshop on HIV Drug Resistance
}

\author{
Carlos Zala MD ${ }^{1}$, Danielle Rouleau MD ${ }^{1}$, Brian Conway MD FRCPC ${ }^{2}$
}

\begin{abstract}
C Zala, D Rouleau, B Conway. Is there anything left to learn? A report on the Fifth International Workshop on HIV Drug Resistance. Can J Infect Dis 1998;9(3):172-176.

Although insight into the viral dynamics of human immunodeficiency virus (HIV) infection has increased dramatically over the past year, there remains much to learn in the field of antiretroviral drug resistance. Transmission of isolates with primary drug resistance is increasingly recognized. With respect to reverse transcriptase inhibitors, it appears that the use of drugs in combination may forestall the development of resistance once therapy has been initiated. Further, certain findings, particularly with respect to zidovudine and lamivudine, suggest that emergence of resistance to one agent may lead to increased susceptibility to another. These data may allow evaluation of innovative treatment strategies to avoid the development of multidrug resistance, which has now been reported in a number of settings. Protease inhibitors (PIs) are, on an individual basis, the most potent antiretroviral compounds available today. A number of studies have shown that resistance to these agents develops after the accumulation of several mutations in the protease gene of HIV. As with reverse transcriptase inhibitors, the use of PIs in the context of regimens designed to suppress viral replication as much as possible appears to forestall, perhaps indefinitely, the development of drug resistance. Although different patterns of resistance mutations have been described for the different PIs available, the issue of cross-resistance remains unresolved. For the time being, it may be best to consider all PIs as a single agent that must always be used in a regimen designed to maximally suppress viral load. In conclusion, research in the field of antiretroviral drug resistance has never been more active and productive. It is hoped that such research will lead to the development of an integrated model of the clinical and laboratory management of HIV-infected individuals.
\end{abstract}

Key Words: Antiretroviral therapy, Drug resistance, Human immunodeficiency virus

\section{Nous reste-t-il quelque chose à apprendre ? Un rapport sur le cinquième Atelier international sur la pharmacorésistance du VIH}

RÉSUMÉ : Bien que la compréhension de la dynamique virale de l'infection au virus de l'immunodéficience humaine ait considérablement évolué au cours de la dernière année, de nombreuses lacunes restent à combler dans le domaine de la pharmacorésistance aux agents antirétroviraux. La transmission d'isolats présentant une pharmacorésistance primaire est de plus en plus reconnue. En ce qui concerne les inhibiteurs de la transcriptase inverse, il semble que l'utilisation d'une combinaison de médicaments peut prévenir le développement d'une résistance une fois que le traitement a débuté. De plus, certains résultats, en particulier ceux concernant la zidovudine et la lamivudine, permettent de croire que l'émergence d'une résistance à un médicament peut entraîner une augmentation de la sensibilité à un autre agent. Ces données pourraient

\footnotetext{
${ }^{1}$ BC Centre for Excellence in HIV/AIDS and ${ }^{2}$ University of British Columbia, Vancouver, British Columbia

Correspondence and reprints: Dr B Conway, University of British Columbia, 1134 Burrard Street, Vancouver, British Columbia, V6Z 1 Y8.

Telephone 604-689-9404,fax604-689-5153,e-mail brian_conway@viridae.com
}

Received for publication July 7, 1997. Accepted September 8, 1997 
permettre d'évaluer des stratégies de traitement innovatrices pour éviter le développement d'une multirésistance médicamenteuse, désormais signalée dans un certain nombre d'endroits. Les inhibiteurs de la protéase sont, actuellement, sur une base individuelle, les composés antirétroviraux les plus puissants. Plusieurs études ont démontré que la résistance à ces agents survient après l'accumulation de plusieurs mutations dans le gène de la protéase du VIH. Pareil aux inhibiteurs de la transcriptase inverse, l'utilisation des inhibiteurs de la protéase, dans le cadre de régimes conçus pour supprimer au maximum la réplication virale, semble prévenir, peut-être indéfiniment, l'apparition d'une pharmacorésistance. Bien que différents schémas de mutations causant une résistance aient été décrits concernant les différents inhibiteurs de la protéase actuels, la question d'une résistance croisée reste sans réponse. Actuellement, il est préférable d'envisager tous les inhibiteurs de la protéase qui sont disponibles comme agent unique devant toujours être utilisé dans un régime visant à supprimer au maximum la charge virale. En conclusion, les recherches dans le domaine de la pharmacorésistance aux antirétroviraux n'ont jamais été aussi actives et productives. On espère que de telles recherches conduiront à la mise au point d'un modèle intégré de la prise en charge clinique et en laboratoire des individus infectés par le VIH.

$\mathrm{O}$ ver the past two years, researchers have become aware that the phase of clinical latency of human immunodeficiency virus (HIV) infection is not accompanied by an arrest of viral turnover. In fact, over $10^{10}$ new virions are produced every day (1). These data have been further refined, using mathematical models that show that the half-life of plasma virions is $6 \mathrm{~h}$ and the average HIV generation time (from release of a virion from a cell in the circulation to its subsequent release from the next cell it infects) is just over two days (2).

Given these dynamics, it is not surprising that plasma viral load decreases very rapidly once appropriate antiretroviral therapy is initiated. This is particularly true if highly effective antiretroviral drug combinations are used, whether these include protease inhibitors (PIs) (3) or non-nucleoside reverse transcriptase inhibitors NNRTIs (4). In many cases, viral load is suppressed to such an extent that the possibility of eventual eradication of HIV from the body is being suggested (5).

It has now clearly been shown that the risk of long term disease progression is directly related to the baseline plasma viral load, even in patients with high CD4 cell counts at the time of their initial evaluation (6). It has also been shown that treatment-induced changes in plasma RNA levels, taken together with CD4 cell counts, are valid predictors of the clinical progression of HIV-related disease (7). Analysis of the large American AIDS Clinical Trials Group (ACTG) 175 trial suggests that, as a single marker, baseline viral load may be the most relevant predictor of ultimate response to nucleoside analogue therapy (8). Further, the magnitude of decrease in viral load is the best predictor of the clinical efficacy of the antiretroviral agents.

With all of this information in mind, it has been suggested that plasma HIV RNA levels be used routinely in clinical practice (9). It is widely held that this approach would improve the care of the HIV-infected patient.

\section{ANTIRETROVIRAL RESISTANCE}

Resistance of clinical HIV isolates to antiretroviral compounds was first described in 1989 (10). A number of studies have suggested that drug resistance is of clinical relevance $(11,12)$ and needs to be considered in any complete virological model of HIV disease. Since 1992, a group of international researchers has met every year to consider the issue and significance of drug resistance. The 1996 meeting, held in conjunction with the XIth International Conference on AIDS, was particularly timely, in light of the renewed emphasis on the use of clinical laboratory measures for individual patient management. As the meeting progressed, it became apparent that, although insight into the significance of viral load has increased dramatically over the past years, there remains much to learn in the field of antiretroviral drug resistance.

\section{REVERSE TRANSCRIPTASE INHIBITORS}

Large American and European trials, which have allowed researchers to appreciate the clinical significance of plasma viral load levels, have also allowed researchers to evaluate the potential significance of antiretroviral drug resistance, most notably to zidovudine (ZDV). At the meeting, reports of both the Delta (Europe/Australia) and ACTG 175 (USA) studies were presented. In both studies, patients received one or more of $\mathrm{ZDV}$, didanosine (ddI) or zalcitabine (ddC). Interestingly, resistance to ddI and ddC was uncommon, even in patients on long term therapy. Of 220 Delta study patients, only 10 were found to have ZDV-resistant isolates (carrying previously described mutations at codons 70 and/or 215 of the reverse transcriptase gene). More complete clinical correlation was established in a group of 89 patients enrolled in ACTG 175. After 56 weeks on ZDV, patients with drug-resistant isolates had experienced a median decline in CD4 counts of 100 cells $/ \mu \mathrm{L}$ and an increase in viral load of $0.5 \log _{10}$ copies/mL plasma. Patients with wild type isolates had a rise of 17 cells $/ \mu \mathrm{L}$ and a decline of $0.4 \log _{10}$ copies $/ \mathrm{mL}$. Although the differences between the groups are relatively unimpressive, they do suggest clinical consequences of drug resistance.

In this context, the possibility of transmission of strains with primary drug resistance is of some concern. In a Swiss cohort of primary HIV infection, nine of 124 patients were found to carry such strains resistant to ZDV. A similar proportion was reported in a Dutch cohort (four of 35), with three of four having been transmitted in the previous year. In Canada, a cross-sectional study of 91 infected children failed to reveal the existence of similar strains, but active ongoing surveillance is required to monitor trends in this field.

Beginning in 1995, the combination of ZDV and lamivudine (3TC) has been widely used in clinical practice. In early studies of 3TC monotherapy, resistance was found to emerge quite readily. Data on the emergence of drug resistance in long term ZDV/3TC combination therapy are now available. NUCA 3001 was a controlled, randomized multicentre study of ZDV versus 3TC versus ZDV/3TC in previously untreated patients. ZDV resistance mutations were identified in eight of $12 \mathrm{pa}$ - 
tients on monotherapy compared with eight of 21 on ZDV/3TC. Resistance to both drugs was present in three patients on combination therapy. In a similar study of drug-experienced individuals (NUCA 3002), six of 34 patients had a dual resistance pattern. Previous data have suggested that the development of 3TC resistance may restore susceptibility to ZDV in previously resistant strains. Nonetheless, in this study, the presence of dual resistance (which may be mediated by a novel mutation at codon 333 of the reverse transcriptase gene) had negative clinical consequences. The prevalence and clinical implications of this phenomenon in patients on ZDV/3TC requires further study.

Reversion of ZDV resistance following the development of resistance to other agents (in addition to 3TC) has been increasingly recognized. Analysis of six isolates from patients receiving foscarnet showed this, as did in vitro experiments with ddI and delavirdine. The significance of these observations was supported by in vitro data showing great difficulty in developing dually resistant isolates to each of the three double drug combinations. These data may allow the evaluation of particularly innovative treatment strategies to minimize the development of antiretroviral resistance in vivo.

Great hope has been placed on the development of new drugs that may be active against isolates resistant to more traditional agents. It is postulated that 1592 U89 is such a drug. Early studies of combination therapy with ZDV have yielded promising results, but multiple mutations have already been described that confer resistance to 1592 U89 and do not resensitize isolates to ZDV. Similar results were reported with other newer agents such as 935U83 and dioxolane guanosine (DXG). In fact, many DXG-resistant isolates were also resistant to ddI, ddC and 3TC.

NNRTIS have been plagued by the rapid development of resistance, particularly when the agents were used as monotherapy. For the first time, an isolate with primary resistance to nevirapine was reported. The search is on for more potent agents that are less susceptible to this problem, and two candidate drugs have been discovered (HBY097 and DMP266). Unfortunately, in vitro experiments show that resistance will still be a problem. Thus, it appears that these drugs will only be useful as part of multidrug regimens, where viral replication is suppressed to such a degree that the emergence of resistance can be delayed.

Finally, there is concern that a 'super' isolate, exhibiting broad spectrum, multidrug resistance (MDR HIV) will emerge. A number of cases of such isolates have been reported in the literature. In a group of patients receiving over 22 months of therapy with combinations of ZDV, ddI and/or ddC, the combination of a mutation at codon 151 with a subset of four others (at codons 62, 75, 77 and 116) conferred high grade resistance in seven of 24 patients. In other studies of 116 patients receiving two or more nucleoside analogues for at least six months, this pattern of resistance (with the codon 152 mutation) was seen in six cases. In more heavily exposed patients, it has been noted that the mutations conferring resistance to 3TC and NNRTIs can easily be superimposed, leading to a truly MDR HIV. Clearly, a monitoring program is needed to establish the
TABLE 1

Different patterns of mutations for the five most studied protease inhibitors

\begin{tabular}{lc} 
Drug & Key resistance mutations (codons) \\
\hline Indinavir & 46,82 \\
Nelfinavir & 30 \\
Ritonavir & $54,71,82,84$ \\
Saquinavir & 48,90 \\
VX-478 & $46,47,50$ \\
\hline
\end{tabular}

prevalence of such strains in the community. This is particularly true because increasingly complex drug regimens are being used routinely.

\section{PIs}

PIs are, on an individual basis, the most potent antiretroviral compounds available today. In vivo, the use of these compounds in appropriate combinations leads to a reduction in circulating plasma viral load in excess of $99 \%$. Three compounds (indinavir, ritonavir and saquinavir) are available in Canada, and a number of others (nelfinavir, vX-478) are in advanced clinical trials. It is clear that an understanding of the development of resistance to these agents will be important to optimize clinical care.

Laboratory and clinical studies have shown that resistance to PIs develops after the accumulation of several mutations in the protease gene leading to amino acid substitutions in both the binding pocket and other regions of this virally encoded enzyme. With drug selection pressure, mutations accumulate sequentially, with each new genomic modification yielding a virus that is less and less susceptible to the agent in question until a fully resistant virus emerges. Different patterns have been described for the five best studied agents (Table 1).

The longest clinical experience is with saquinavir. Analysis of plasma virus sequences in 39 patients receiving high dose saquinavir for 24 weeks showed that, in addition to the mutations at codons 48 and 90, additional changes at codons 10 , 54, 63 and 71 were present. Although these changes themselves do not alter drug susceptibility, they may be important in 'stabilizing' the virus and allowing it to maintain its ability to replicate as it becomes resistant. This hypothesis is supported by in vitro experiments that show decreased replication efficiency of a wild type virus strain into which the mutations at codon 48 and 90 were artificially introduced.

An analogous pattern has been described for indinavir. Although mutations at codons 46 and 82 best approximate quantitative decreases in drug susceptibility, the appearance or maintenance of these mutations is enhanced by the preexistence or appearance of other sequence changes, such as at codon 93. Similar work done with ritonavir shows that the maximal development of resistance follows a complex series of genetic changes, involving as many as nine different codons.

The potential loss of susceptibility of HIV to the 'best' drugs is problematic. It should be understood that resistance only develops with ongoing viral replication in the presence of 
a given drug. It is not surprising that isolates taken from patients treated with suboptimal doses of indinavir (in early dose-ranging studies) were more likely to become resistant than isolates from patients who initiated therapy at an optimal dose. Similarly, pharmacokinetic analyses have demonstrated a significant inverse relationship between trough plasma concentrations of ritonavir and the emergence of drug resistance. Thus, PIs are best used in the context of regimens that suppress viral replication as effectively as possible.

Preliminary data suggest that this goal may be achieved by the combined use of PIs with reverse transcriptase inhibitors. In a group of patients receiving ZDV, ddI and indinavir, the prevalence of indinavir resistance was greatly reduced over 24 weeks of observation compared with patients receiving indinavir alone (two of 20 versus 13 of 24 patients, $\mathrm{P}=0.003$ ). This approach also seems to reduce the emergence of resistance to ZDV and ddI compared with a regimen omitting indinavir ( 0 of 20 versus 10 of 16 patients with resistant isolates in one study). The use of 'fully suppressive regimens' may hold the key to obtaining optimal clinical responses because of their ability to delay (perhaps indefinitely) the emergence of drug resistance. The combination of ritonavir and saquinavir may also accomplish the same goals. In light of the favourable pharmacokinetic interactions between the two compounds, the dose of both drugs (particularly saquinavir) can be greatly reduced without sacrificing drug efficacy. This may improve compliance with therapy, a key issue in maintaining therapeutic effectiveness.

Finally, the issue of cross-resistance among the different PIs merits attention. This is particularly important when the approach to secondary drug combinations in patients failing a PI-containing regimen is considered. As such, there appears to be absolute cross-resistance between indinavir and ritonavir. It was initially thought that the majority of isolates resistant to saquinavir remained susceptible to the other PIs, but this may not be correct. The results of a clinical trial of indinavir in patients with saquinavir-resistant isolates suggests that it will be difficult to use these agents sequentially and expect the second regimen to be effective.. The different resistance pathways for the newer agents (particularly nelfinavir) are encouraging in terms of the issue of cross-resistance, but this will have to be verified before any definitive statements can be made. For the time being, it may be best to consider all PIs as a single agent that must always be used in a regimen designed to suppress viral load maximally.

\section{CONCLUSION}

Research in the field of antiretroviral drug resistance has never been more active and productive. As new reverse transcriptase inhibitors are developed and evaluated, mutations conferring resistance to them are identified. An understanding of evolutionary limitations on genetic variability of the reverse transcriptase molecule may lead to more insightful protocols for the use of these agents in clinical practice. Although we will need to better understand the patterns of emergence of resistance and cross-resistance among all the drugs available, certain general trends have emerged. The use of PIs (or other agents) in conjunction with the more traditional nucleoside analogues may suppress viral replication so effectively that drug resistance may be delayed or prevented. We expect that this delay in the emergence of resistance will prolong the clinical efficacy of our newer drug regimens. This being said, we must remain aware of the possibility of MDR 'super strains' developing, as more complex combination therapy regimens gain widespread acceptance.

It appears that drug resistance testing will be relevant in the clinic. More practical methods for its measurement are being developed and may facilitate the widespread introduction of such testing. In parallel, more basic research is continuing to expand our understanding of how susceptible and resistant viral isolates may coexist in vivo, with varying degrees of drug pressure being applied. This knowledge may guide treatment strategies in the face of different levels or characteristics of drug resistance.

An air of optimism reigned at the XIth International Conference on AIDS. Much of this related to our increased understanding of viral load and its clinical significance. Judging frm the data presented at the Fifth International Workshop on HIV Drug Resistance, there remains much to learn. We propose four specific goals for the two years:

Establishment of in vitro modelling experiments to determine potential mutational limitations of HIV, with a view to exploiting such limitations in the therapeutic arena. Within the next two year, enough data should be available to design a clinical trial based on this hypothesis.

Monitoring of clinical isolates for multidrug resistant HIV strains. Within the two years, with international collaborative efforts, enough data should be available to assess the true magnitude of the problem, especially for incident infections.

Evaluation of the usefulness of drug resistance testing in clinical practice. Within the two years, enough data should be available to initiate a prospective pilot study of clinical decision-making based on resistance test results.

Development of an integrated model of the clinical and laboratory management of HIV-infected individuals, combining concepts of clinical and immunological evaluations with viral load and drug resistance testing. Although such a complex model is not expected to emerge (at least in its most complete form) over the next year, we must not lose sight of it as our ultimate goal.

In this context, it is hoped that with ongoing efforts to improve our understanding of antiretroviral drug resistance, the optimism of the XIth International AIDS Conference will be carried forward to its XIIth incarnation in Geneva.

ACKNOWLEDGEMENTS: We thank Deborah Hamann-Trou, Ramona Gomes and Alice Eslava for their administrative assistance. 


\section{REFERENCES}

1. Ho DD, Neumann AU, Perelson AS, Chen W, Leonard JM, Markowitz M. Rapid turnover of plasma virions and CD4 lymphocytes in HIV-1 infection. Nature 1995;373:123-6.

2. Perelson AS, Neumann AU, Markowitz M, Leonard JM, Ho DD. HIV-1 dynamics in vivo: virion clearance rate, infected cell life-span and viral generation time. Science 1996;271:1582-6.

3. Gulick R, Mellors J, Havlir D, et al. Potent and sustained antiretroviral activity of indinavir in combination with zidovudine and lamivudine. 3rd Conference on Retroviruses and Opportunistic Infections, 1996. Washington, DC, January 28 to February 1, 1996. (Abst LB7)

4. Conway B, Montaner JSG, Cooper D, et al. Randomized, double-blind one year study of the immunologic and virologic effects of nevirapine, didanosine and zidovudine combinations among antiretroviral naive, AIDS-free patients with CD4 200-600. AIDS 1996;10(Suppl 2):S15. (Abst)

5. Pennisi E, Cohen J. Eradicating HIV from a patient: not just a dream? Science 1996;272:1884.

6. Mellors JW, Munoz A, Giorgi JV, et al. Plasma viral load and CD4 lymphocytes as prognostic markers of HIV-1 infection. Ann Intern Med 1997;126:946-54.

7. O'Brien WA, Hartigan PM, Martin D, et al. Changes in plasma
HIV-1 RNA and CD4 lymphocyte counts and the risk of progression of AIDS. N Engl J Med 1996;334:426-31.

8. Katzenstein DA, Hammer SM, Hughes MD, et al. The relation of virologic and immunologic markers to clinical outcomes after nucleoside therapy in HIV-infected adults with 200 to 500 CD4 cells per cubic millimeter. AIDS Clinical Trials Group Study 175 Virology Study Team. N Engl J Med 1996;335:109-18.

9. Carpenter CC, Fischl MA, Hammer SM, et al. Antiretroviral therapy for HIV infection in 1996. Recommendations of an international panel. International AIDS Society-USA. JAMA 1996;276:146-54

10. Larder BA, Darby G, Richman DD. HIV with reduced sensitivity to zidovudine (AZT) isolated during prolonged therapy. Science 1989;243:1731-4.

11. Montaner JSG, Singer J, Schechter MT, et al. Clinical correlates of in vitro HIV-1 resistance of zidovudine. Results of the Multicentre Canadian AZT Trial. AIDS 1993;7:189-96.

12. D'Aquila RT, Johnson VA, Welles SL, et al. Zidovudine resistance and HIV-1 disease progression during antiretroviral therapy. AIDS Clinical Trials Group Protocol 116B/117 Team and the Virology Committee Resistance Working Group. Ann Intern Med $1995 ; 122: 401-8$ 


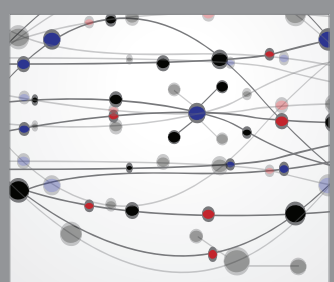

The Scientific World Journal
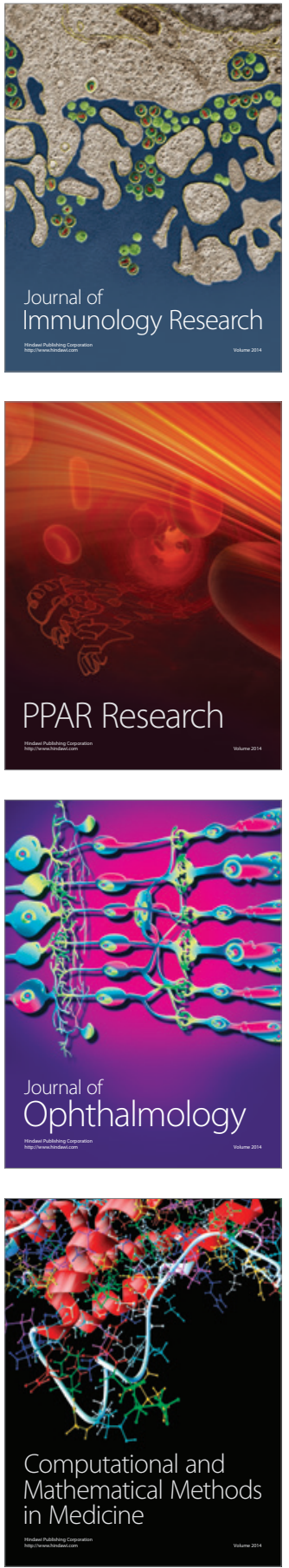

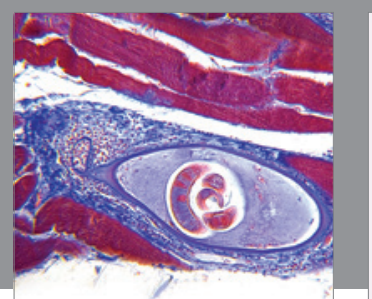

Gastroenterology Research and Practice

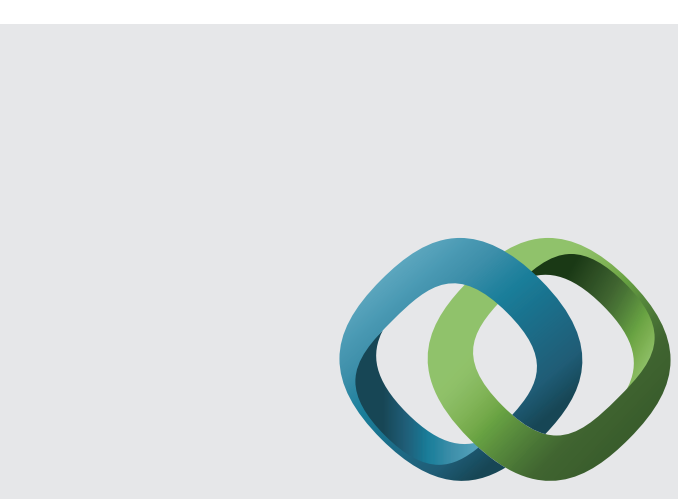

\section{Hindawi}

Submit your manuscripts at

http://www.hindawi.com

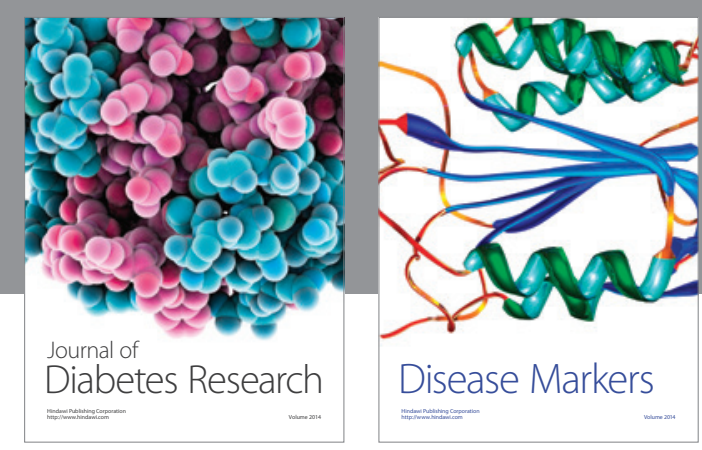

Disease Markers
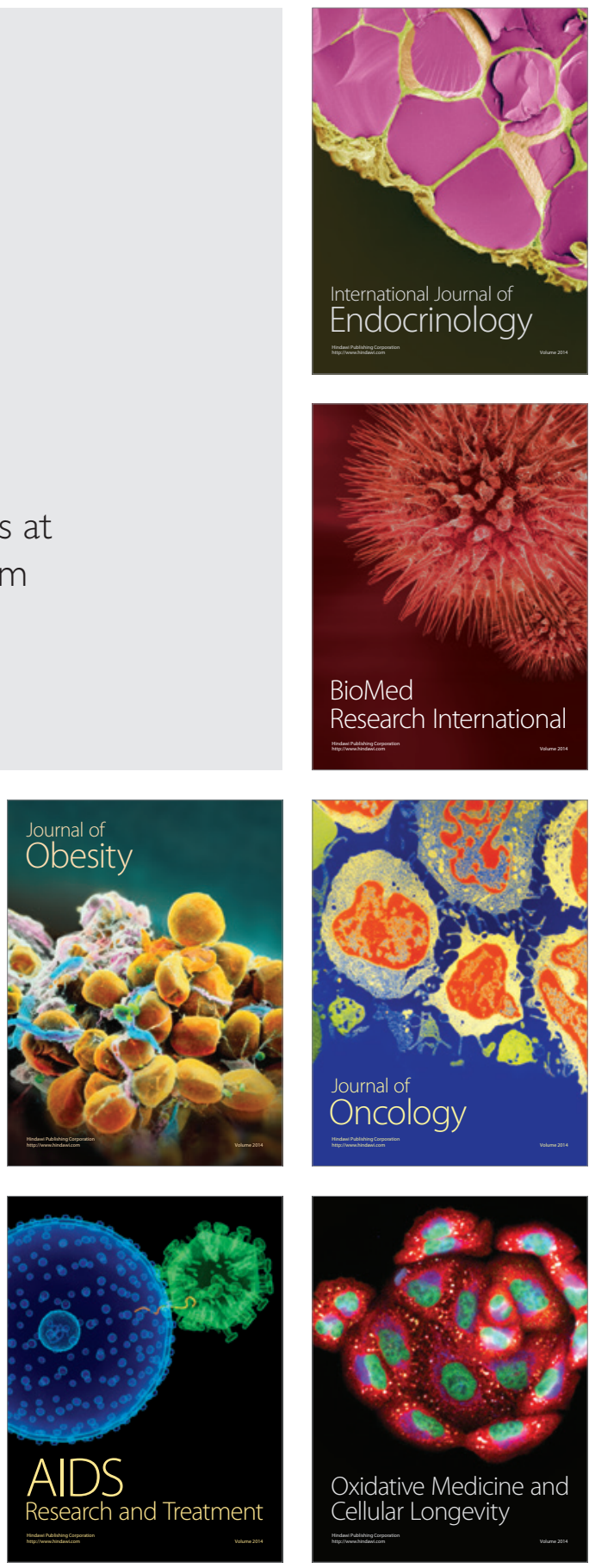